\title{
Enhanced triisopropylbenzene cracking and suppressed coking on tailored composite of Y-zeolite/amorphous silica-alumina catalyst
}

\author{
M.S. Aghakhani ${ }^{a}$, A.A. Khodadadi a,b,*, Sh. Najafi ${ }^{a}$, Y. Mortazavi ${ }^{\text {a,b,* }}$ \\ a School of Chemical Engineering, College of Engineering, University of Tehran, P.O. Box 11155/4563, Tehran, Iran \\ ${ }^{\mathrm{b}}$ Oil and Gas Processing Center of Excellence, University of Tehran, P.O. Box 11155/4563, Tehran, Iran
}

\section{A R T I C L E I N F O}

\section{Article history:}

Received 2 May 2013

Received in revised form 26 October 2013

Accepted 10 November 2013

Available online 15 November 2013

\section{Keywords:}

Catalytic composite

Y-Zeolite

Amorphous silica-alumina

Catalytic cracking

\begin{abstract}
A B S T R A C T
Catalytic composites of Y-zeolite-amorphous silica-alumina (ASA) were prepared by four different methods to enhance pre-cracking and cracking of triisopropylbenzene (TIPB). TIPB cracking on composite catalysts were compared with a conventionally prepared catalyst. The samples were characterized by FESEM, XRD, $\mathrm{N}_{2}$-adsorption and $\mathrm{NH}_{3}$-TPD. The catalysts performance was evaluated by triisopropylbenzene cracking at $350^{\circ} \mathrm{C}$ in a fixed bed reactor. The coke content of the catalysts was measured by TPO. Compared to the conventional catalyst, significantly deeper cracking to benzene of about $117 \%$ higher, up to $62 \%$ lower amount of coke, and lower deactivation rate are observed for the composite catalysts.
\end{abstract}

๑ 2013 The Korean Society of Industrial and Engineering Chemistry. Published by Elsevier B.V. All rights reserved.

\section{Introduction}

A significant synergism between constituent parts is observed in carefully tailored composites, particularly in those made for the field of catalysis. In this regard, the diffusion rate can be enhanced [1] and characteristics of the reactants or products such as the chain lengths and spatial configuration of their molecules can be finely tuned resulting in higher selectivity towards the desired products [2-8]. For instance, catalytic composite of ZSM-5 containing silica-alumina is used to enhance the product's octane number in VGO cracking [2]. Conversion of phenol is shown to be considerably enhanced by using a catalytic composite of MCM/Yzeolite [3]. Octane index of Fisher-Tropsch products is improved by applying a catalyst consisting of a HZSM-5 zeolite shell, which is formed around the core of $\mathrm{Co}, \mathrm{Fe}$, and $\mathrm{Ru} / \mathrm{SiO}_{2}[6,7]$. As another example, a higher catalytic performance is reported in water-gas shift reaction for a core-shell catalyst comprising a noble metal as core and ceria as shell [8].

Fluid catalytic cracking (FCC) units as one of the major industrial consumers of catalysts is a potential market for such advanced composite catalysts. The FCC catalysts are composed of

\footnotetext{
* Corresponding author at: University of Tehran, School of Chemical Engineering, College of Engineering Tehran, Tehran 11365/4563, Iran. Tel.: +98 21 66967793; fax: +982166967793.

E-mail addresses: khodadad@ut.ac.ir (A.A. Khodadadi), mortazav@ut.ac.ir (Y. Mortazavi).
}

crystalline Y-zeolite, active matrices, low activity fillers, binders, and some other additives. The inventory of FCC units includes a large amount of catalysts for cracking of mainly atmospheric and vacuum gas oils to more valuable products such as gasoline. Since the proper feedstocks for FCC units are being replaced with heavier oil cuts, a number of challenges associated with the FCC catalysts need to be addressed. Heavier feeds of FCC units contain a wide variety of unsaturated species with higher tendency to coke formation. It has been shown that addition of mesoporous and/or macroporous materials to the matrix of FCC catalysts enhances the catalyst yield and selectivity towards desired products [9-11]. While the macropores contribute to converting the non-vaporized portion of the feed, the mesopores adjust the molecules' sizes to a range suitable for diffusion into the zeolite pores [10]. In addition, the macro/mesoporous materials act as metal traps making the poisoning metals unable to enter the zeolite pores and destruct its crystalline structure. Furthermore, an active matrix of the FCC catalysts should have a proper pore size and acid density not only to pre-crack the heavier portions of the feeds but also to decrease the coke formation tendency of the catalysts. Different composites of zeolites, such as MCM-41/FAU, MFI/MCM-41, MCM-41/ $\beta$, NaY/ $\beta$, and MCM-41/NaY, have been introduced to have the proper acidity and pore structure to be used in hydrocracking and cracking of vacuum gasoil [12-16].

With respect to our previous work [17], in which we put a bed of amorphous silica-alumina upstream of the same bed of Y-zeolite in a fixed bed reactor and found that activity of the catalyst for cracking of triisopropylbenzene (TIPB) to deep cracking products, 
i.e., benzene and cumene, is sharply enhanced and the coke formation tendency of the catalyst is considerably suppressed, we synthesized a set of tailored composites of silica-alumina/Yzeolite catalysts. Different routes were employed in order to prepare the new tailored composite catalysts. The prepared samples were characterized and compared to find a catalyst with the maximum yields of benzene and cumene in cracking of TIPB. When Y-zeolite is covered with the mesoporous amorphous silicaalumina, higher TIPB cracking activity and lower rate of coke formation are expected.

\section{Experimental}

Materials used in this investigation are as follows: sodium silicate solution (Merck), sodium aluminate powder (Riedel-de Haën), sodium hydroxide (Merck), aluminum sulfate (Merck), polyvinyl alcohol (PVA, Merck), poly dialyl dimethyl ammonium chloride (PDDA, 20 wt.\% solution, Aldrich), ammonium nitrate (Merck), nitric acid (65 wt.\% solution, Merck), hydrochloric acid (32 wt.\%, Merck), sulfuric acid (95-97 wt.\%, Merck), tri-isopropyl benzene (TIPB, 96\%, Merck). Deionized water (DW) was used to prepare all aqueous solutions and wash the samples.

\subsection{Synthesis of Y-zeolite}

$\mathrm{NaY}$ zeolite was obtained by aging a gel with final molar composition of $4.62 \mathrm{Na}_{2} \mathrm{O}: 1 \mathrm{Al}_{2} \mathrm{O}_{3}: 10 \mathrm{SiO}_{2}: 180 \mathrm{H}_{2} \mathrm{O}$ at $25^{\circ} \mathrm{C}$ for $24 \mathrm{~h}$ followed by crystallization in an autoclave at $100^{\circ} \mathrm{C}$ for $6 \mathrm{~h}$. The sample was washed with DW and centrifuged repeatedly to reach $\mathrm{pH} 7$ and then dried at $100^{\circ} \mathrm{C}$ overnight. Ammonium form of the synthesized zeolite, i.e., $\mathrm{NH}_{4} \mathrm{Y}$, was obtained by stirring $5.0 \mathrm{~g}$ of the $\mathrm{NaY}$ zeolite with $50.0 \mathrm{ml}$ of $1.5 \mathrm{M}$ ammonium nitrate aqueous solution under total reflux condition at $90^{\circ} \mathrm{C}$ for two times, each time last $3 \mathrm{~h}$. Finally, the $\mathrm{NH}_{4} \mathrm{Y}$ zeolite was washed, centrifuged and then dried at $110^{\circ} \mathrm{C}$ overnight.

\subsection{Preparation of the conventionally incorporated catalyst (CI)}

A catalyst with 50.0 wt.\% $\mathrm{NH}_{4} \mathrm{Y}$ zeolite and $50.0 \mathrm{wt} . \%$ amorphous silica-alumina (ASA, $13.0 \mathrm{wt} . \%$ alumina) was prepared by the conventional incorporation technique as the reference sample. The ASA gel was separately synthesized by co-precipitation of two solutions as follows: the first solution was prepared by stirring of $0.46 \mathrm{~g}$ aluminum sulfate with $0.6 \mathrm{ml} \mathrm{HCl}$ solution (32.0 wt.\%) and $15 \mathrm{ml} \mathrm{DW}$, and the second was prepared by dilution of $2.32 \mathrm{~g}$ sodium silicate solution with $25 \mathrm{ml} \mathrm{DW}$. The second solution was added drop-wise to the first solution under vigorous mixing to form the final ASA translucent gel. $2.0 \mathrm{~g} \mathrm{NH}_{4}$ Y zeolite crystals were added slowly to the as prepared ASA gel under mixing. The final slurry was washed, centrifuged thoroughly and then dried at $110^{\circ} \mathrm{C}$ overnight.

\subsection{Surface charge modified zeolite (SCM)}

The negative surface charge of the $\mathrm{NH}_{4} \mathrm{Y}$ zeolite crystals was reversed by using a $0.5 \mathrm{wt}$.\% aqueous solution of PDDA. In this course, 50.0 g slurry of $\mathrm{NH}_{4} \mathrm{Y}$ zeolite containing $2.0 \mathrm{wt}$.\% zeolite crystals was dispersed thoroughly by ultrasonication and stirred with $1.25 \mathrm{~g}$ PDDA (20 wt.\% solution) for $1 \mathrm{~h}$ and then washed with DW and centrifuged in order to remove any extra or weakly-bound species from the surface of the crystals. Finally, the surface charge modified $\mathrm{NH}_{4} \mathrm{Y}$ zeolite was re-dispersed in DW to form slurry of $2.0 \mathrm{wt}$ \% positive surface charge $\mathrm{NH}_{4} \mathrm{Y}$ zeolite. This slurry was further used in preparation of all composite catalysts.

\subsection{Preparation of composite catalysts}

The synthesis procedures of composite catalysts through four routes are shown schematically in Fig. 1. All of the composite samples were prepared from similar starting materials, i.e., ASA/ zeolite of $1 / 1$. After preparation of each sample, they were kept at $80^{\circ} \mathrm{C}$ for $6 \mathrm{~h}$, separated and washed to neutral $\mathrm{pH}$ by several times centrifugation followed by drying at $110^{\circ} \mathrm{C}$ overnight to obtain the sample in the powder form, referred to as powderizing.

\subsubsection{ASA precipitated on $\mathrm{NH}_{4} \mathrm{Y}$ zeolite (PCS)}

A solution similar to the first solution used in preparation of ASA gel was vigorously mixed with $50.0 \mathrm{~g}$ of $2.0 \mathrm{wt}$.\% slurry of the $\mathrm{SCM}-\mathrm{NH}_{4} \mathrm{Y}$ zeolite. A solution the same as the second solution used in preparation of ASA gel was added drop-wise to the above slurry

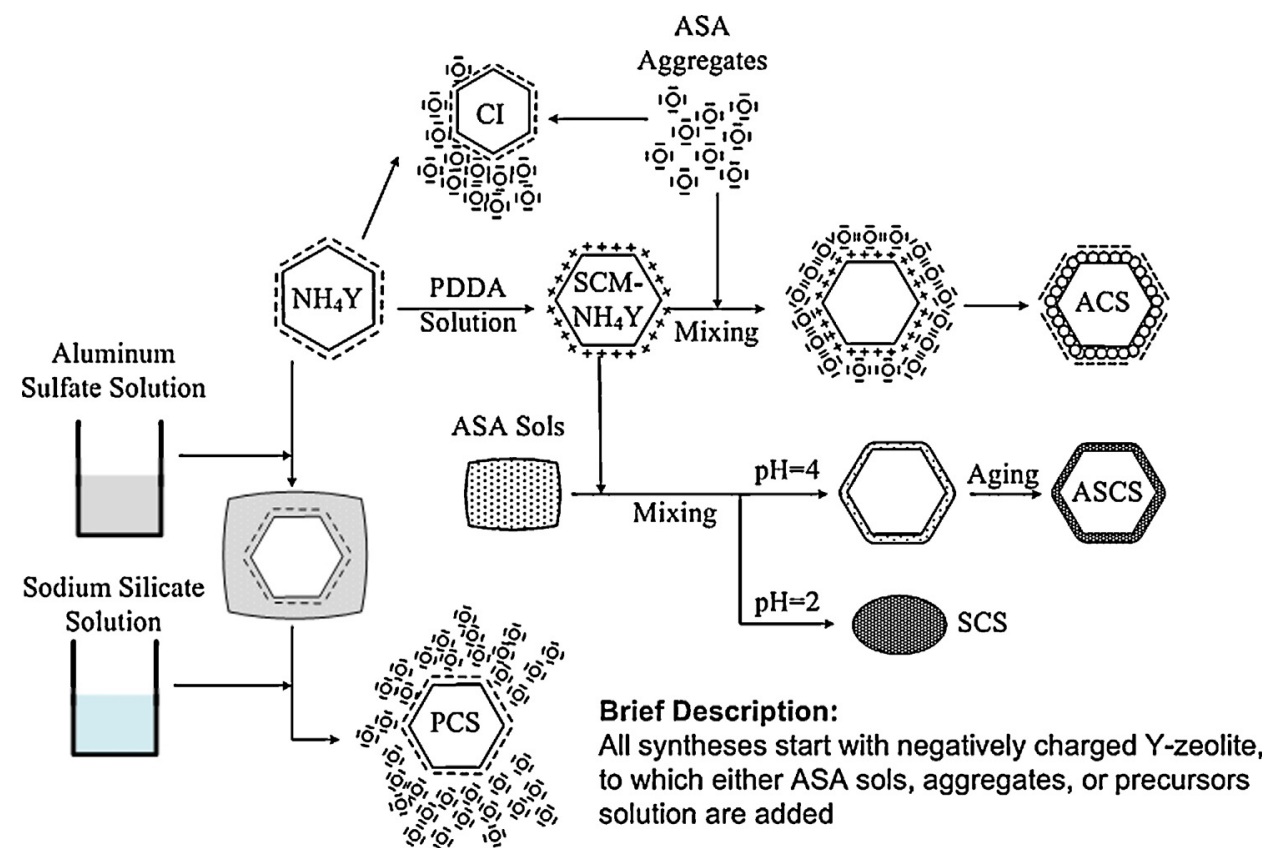

Fig. 1. The synthesis routes of CS composites. 
under vigorous mixing to form the final composite slurry and then powderized.

\subsubsection{ASA aggregates deposited on $\mathrm{NH}_{4} \mathrm{Y}$ zeolite (ACS)}

The ASA gel was aged for $48 \mathrm{~h}$ at room temperature, washed, centrifuged, and dried at $120^{\circ} \mathrm{C}$ for $3 \mathrm{~h}$ to form ASA aggregates, which were then twice ion-exchanged, each time with $0.5 \mathrm{M}$ ammonium nitrate solution under similar condition described before. $50.0 \mathrm{~g}$ of $2.0 \mathrm{wt} . \%$ slurry of ASA aggregates and $0.2 \mathrm{wt} . \%$ of PVA solution as stabilizing agent were fully dispersed by ultrasonication. 50.0 g SCM- $\mathrm{NH}_{4} \mathrm{Y}$ zeolite slurry was added dropwise to the dispersed ASA slurry under mixing and the resulted slurry was then powderized.

\subsubsection{ASA sols deposited on $\mathrm{NH}_{4} \mathrm{Y}$ zeolite (SCS)}

ASA sol was synthesized as follows; a diluted solution of sodium silicate was obtained by $2.14 \mathrm{~g}$ sodium silicate and $20 \mathrm{ml} \mathrm{DW}$, and added to a solution of $0.47 \mathrm{~g}$ aluminum sulfate and $0.5 \mathrm{ml}$ sulfuric acid (95-97.0 wt.\%) in $15 \mathrm{ml}$ DW. 50.0 g SCM- $\mathrm{NH}_{4} \mathrm{Y}$ zeolite slurry added slowly to ASA sol under mixing. The final composite slurry with $\mathrm{pH}$ of 2 was powderized.

\subsubsection{ASA sols deposited-aged on $\mathrm{NH}_{4} \mathrm{Y}$ zeolite (ASCS)}

The sample was prepared similar to SCS except that the $\mathrm{pH}$ of final composite slurry was adjusted at 4 and the final composite slurry was aged at room temperature for $60 \mathrm{~h}$ before being powderized.Finally, all catalyst samples were ion-exchanged with $1.0 \mathrm{M} \mathrm{NH}_{4} \mathrm{OH}$ solution under similar condition described before and calcined at $550^{\circ} \mathrm{C}$ for $4 \mathrm{~h}$.

\subsection{Characterization of the samples}

Field emission scanning electron microscopy (FESEM) was done by a Hitachi S-4160 instrument to measure the particle size and study the morphology of the samples after coating them with gold. The particle size distribution and the mean size of particles for each sample were statistically obtained from FESEM images based on graphical methods. X-ray powder diffraction (XRD) was done by Philips PW 1840 using Cu K $\alpha 1(1=1.54056 \AA)$ radiation in the $2 \theta$ range of $5-50^{\circ}$ and at a scanning rate of $0.01(2 \theta) / \mathrm{s} . \mathrm{N}_{2}$ adsorptiondesorption were obtained using Micromeritics ASAP 2010 at the liquid nitrogen temperature. The samples were characterized after degassing at $300^{\circ} \mathrm{C}$ for $3 \mathrm{~h}$. The mesoporous structure was determined from desorption branch of isotherms by the BJH method, while the micro porous structure was obtained from the $t$ plot analysis of the adsorption branch of the isotherms. Pore size distributions were obtained using the BJH model. Temperatureprogrammed desorption (TPD) of ammonia was carried out using a Quantachrome CHEMBET-3000 apparatus equipped with a microTCD detector. First, samples were degassed at $475^{\circ} \mathrm{C}$ for $3 \mathrm{~h}$ under $20 \mathrm{sccm}$ of He flow. Adsorption of anhydrous ammonia (Merck) was carried out at $100^{\circ} \mathrm{C}$ by exposing the activated samples to $20 \mathrm{sccm} \mathrm{NH} /$ He mixture (5.0 vol.\% ammonia balanced with $\mathrm{He}$ ) for $1.5 \mathrm{~h}$. After flushing the physically bound $\mathrm{NH}_{3}$ at $100^{\circ} \mathrm{C}$, ammonia TPD was performed at a heating rate of $10^{\circ} \mathrm{C} / \mathrm{min}$ from 100 up to $550^{\circ} \mathrm{C}$ under He flow.

\subsection{Cracking activity measurement}

TIPB cracking activity of the samples was evaluated at $350^{\circ} \mathrm{C}$ in an experimental setup described elsewhere [17]. A quartz microreactor (12 $\mathrm{mm}$ ID) was used for the cracking experiments. The reactor was loaded with a bed of $0.1 \mathrm{~g}$ of the catalyst particles (50-120 mesh size) in which the catalysts were activated in situ at $475^{\circ} \mathrm{C}$ under $40 \mathrm{sccm}$ flow of dry air for $3 \mathrm{~h}$. The TIPB was injected by a syringe pump over the $20 \mathrm{ml}$ quartz chips placed above the catalyst bed to prepare a gas mixture of 5.0 vol.\% TIPB/Ar as the feed for the cracking experiments. The reactor effluents were analyzed online by a gas chromatograph (Perkin-Elmer GC-8410) equipped with a flame ionization detector (FID) and a packed column with silicone oil SE-30 (25.0\%) on Chromosorb P. TIPB cracking tests at $350^{\circ} \mathrm{C}$ were performed to investigate diffusional constraints of samples. No thermal cracking of TIPB was observed at this temperature [17].

\subsection{Evaluation of coked samples}

After the TIPB cracking experiments, the coke content of the catalysts was estimated by temperature-programmed oxidation (TPO) technique. TPO patterns of $0.1 \mathrm{~g}$ of the coked catalysts were obtained in a setup described in our previous work [17], using 5.0 vol.\% $\mathrm{O}_{2}$ in $\mathrm{N}_{2}$ as oxidant with a total flow rate of $80 \mathrm{sccm}$. The reaction products were monitored instantaneously using an online FTIR instrument. FTIR measurements were performed by a Bruker Vector22 spectrometer equipped with a gas cell $(8 \mathrm{~mm}$ ID and $100 \mathrm{~mm}$ length) with $\mathrm{KBr}$ windows. The FTIR was used in transmission mode with a resolution of $5 \mathrm{~cm}^{-1}$ in the range of $4000-400 \mathrm{~cm}^{-1}$. Peak areas in the ranges of $2400-2280 \mathrm{~cm}^{-1}$ and $2235-2030 \mathrm{~cm}^{-1}$ were used for $\mathrm{CO}_{2}$ and $\mathrm{CO}$, respectively. The calibration was done using 2000 and $1000 \mathrm{ppm}$ of $\mathrm{CO}_{2}$ and $\mathrm{CO}$, respectively.

\section{Results and discussion}

\subsection{Characterization}

FESEM images of $\mathrm{NH}_{4} \mathrm{Y}$ zeolite, ASA, the conventionally incorporated (CI) catalyst and the composite catalysts (CS) are shown in Fig. 2. The zeolite (Fig. 2a) with cubic crystal system consists of agglomerated particles with smooth surface and sharp edges having average particle size of $0.7 \mu \mathrm{m}$ while silica-alumina (Fig. 2b) is amorphous and shows rough surface irregular agglomerates with sizes in the range of $0.2-2 \mu \mathrm{m}$. The FESEM image of CI sample (Fig. 2c) shows distinct particles of the zeolite and agglomerates of ASA as well as combinations of both. This indicates that the zeolites particles are not thoroughly covered by ASA particles in CI sample similar to the common FCC catalysts prepared via a conventional incorporation technique. The FESEM images of CS samples show the coverage of the zeolite with ASA particles. In the PCS (Fig. 2d) the zeolites are partially covered with ASA agglomerates since the formation of ASA particles through rapid co-precipitation reactions may not exclusively occur on the zeolite particles. In this composite sample, the average size of the ASA-covered zeolite particles is seen to be about $1.2 \mu \mathrm{m}$. The ACS composite (Fig. 2e) shows particles with rough surfaces and the average size of $1.0 \mu \mathrm{m}$. In this image, it is clearly seen that the zeolite particles are covered with ASA. The other CS composites, shown in Figs. 2f and g, which are synthesized by using ASA sols have smoother surfaces as compared with the ACS sample. This may be attributed to the smaller sols rather than larger particles of ASA covering the zeolites. The average particle size of SCS and ASCS are 1.1 and $1.3 \mu \mathrm{m}$, respectively. As a result, the thickness of formed shell for ASCS is larger than SCS due to the aging period in the preparation process of the ASCS sample.

The XRD patterns of $\mathrm{NH}_{4} \mathrm{Y}$ zeolite, ASA, the CI catalyst and the CS composites are illustrated in Fig. 3. The characteristic peaks and Miller indices of Y-zeolite are shown on the $\mathrm{NH}_{4} \mathrm{Y}$ diffractogram according to the ASTM D3906. The cell parameter and Si/Al ratio of the zeolite were calculated from the XRD pattern based on the methodology used in the literature [18]. The XRD pattern of the synthesized $\mathrm{NH}_{4} \mathrm{Y}$ zeolite shows only the Y-zeolite structure. The cell parameter and Si/Al ratio of the $\mathrm{NH}_{4} \mathrm{Y}$ zeolite are 24.80 and 

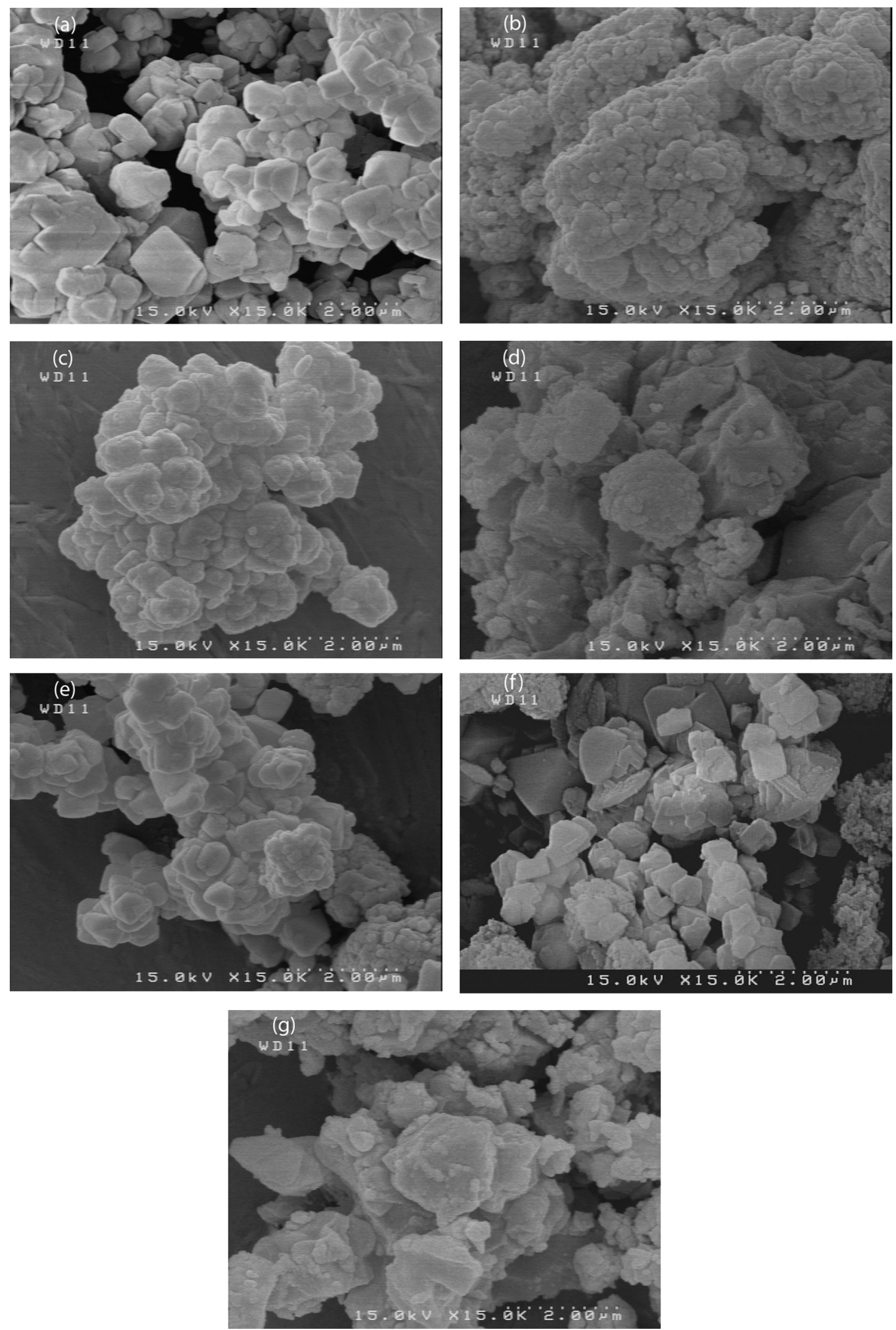

Fig. 2. FESEM images of the samples: (a) $\mathrm{NH}_{4} \mathrm{Y}$ zeolite, (b) ASA, (c) the CI catalyst, (d) PCS, (e) ACS, (f) SCS, and (g) ASCS.

$2.18 \AA$, respectively. The average crystallite size of zeolite was determined to be $0.7 \mu \mathrm{m}$ by applying image analysis technique on FESEM image of $\mathrm{NH}_{4} \mathrm{Y}$ zeolite. No peak in the XRD pattern of ASA is observed, indicating the formation of amorphous silica-alumina
[19]. For the CI catalyst and all of the CS composites, except for the SCS, crystalline pattern with the same diffraction peak positions but with smaller intensities/background ratios is observed. The main source for the appearance of the background and lower peak 


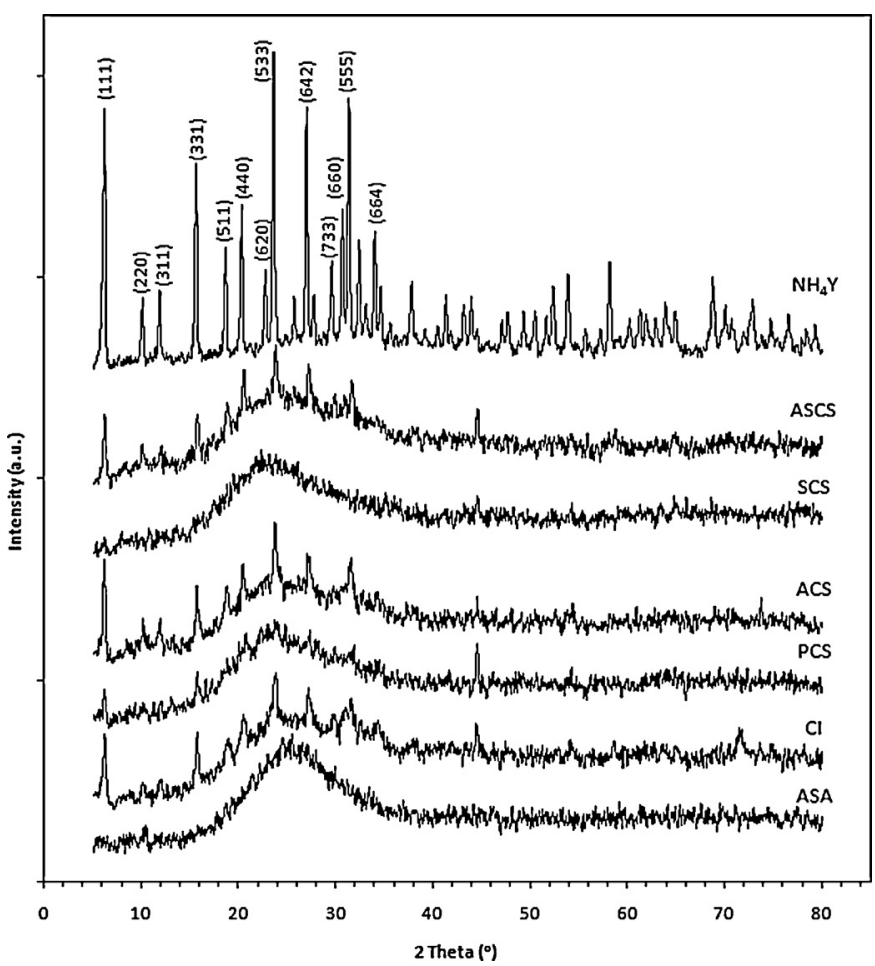

Fig. 3. XRD patterns of $\mathrm{NH}_{4} \mathrm{Y}$ zeolite, ASA, CS composites, and the CI catalyst.

intensities in the XRD patterns is the amorphous silica-alumina. It should be noted that there are no significant shifts in the peak positions of the $\mathrm{CS}$ composites compared to that of $\mathrm{NH}_{4} \mathrm{Y}$ zeolite, suggesting that the cell parameter of the zeolite part remains almost constant during the synthesis [20]. Thus, the increase in the particle size of the CS composites is attributed to the presence of ASA particles, which covers the zeolite particles while not changing the cell parameter and particle size of them.

No crystalline pattern is detected for the SCS sample, indicating the destruction of the crystalline structure of its zeolitic part at harsh synthesis condition of low $\mathrm{pH}$. It has been reported that Yzeolite crystals dissolve non-stoichiometrically in low $\mathrm{pH}$ solutions [21]. Structural Al atoms of Y-zeolite are dissolved in acidic solutions while its framework $\mathrm{Si}$ atoms are not, changing the structure of Y-zeolite from crystalline to amorphous [21]. In the course of ASCS synthesis compared to the SCS sample, it is expected that increase in $\mathrm{pH}$ preserves the crystalline structure of $\mathrm{NH}_{4} \mathrm{Y}$ zeolite. In addition, the lower intensity of peaks for ASCS compared to ACS may be attributed to the existence of higher amounts of ASA, which is grown on the zeolites during the longer aging period.

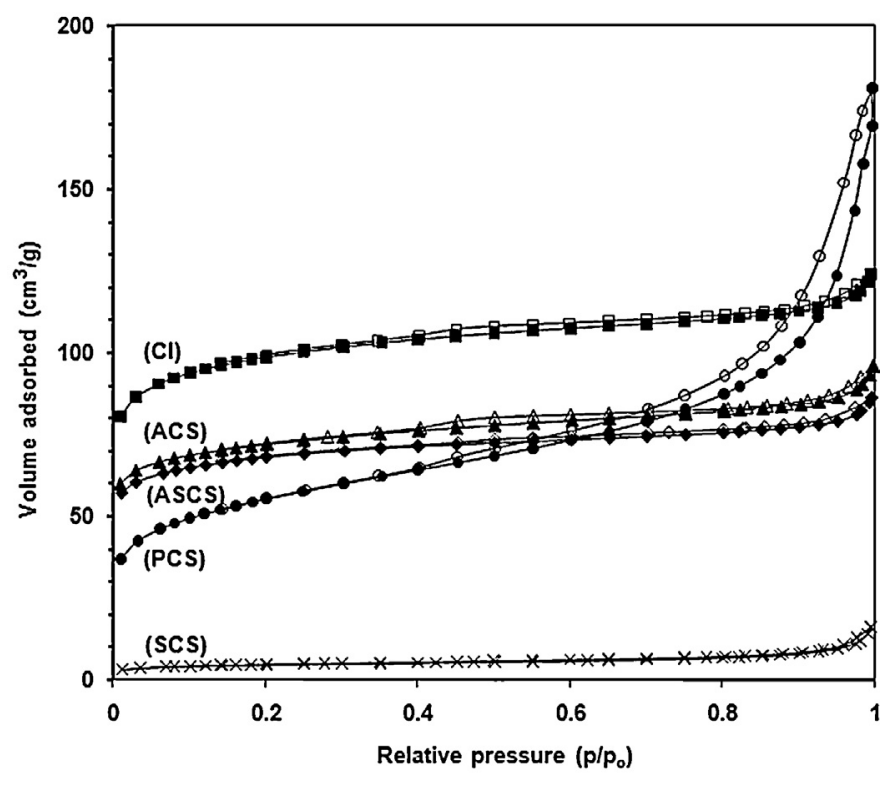

Fig. 4. $\mathrm{N}_{2}$ adsorption-desorption isotherms of various samples.

The textural properties of the samples are summarized in Table 1 . The synthesized $\mathrm{NH}_{4} \mathrm{Y}$ zeolite is a microporous material while the ASA sample shows a meso- and macroporous structure. This structure is formed by the silica-alumina interparticle void spaces in the ASA agglomerates. BET surface areas of $\mathrm{NH}_{4} \mathrm{Y}$ zeolite, ASA and the CI catalyst are 675,196 , and $369 \mathrm{~m}^{2} / \mathrm{g}$, respectively. Harsh synthesis condition of low $\mathrm{pH}$ in the preparation of SCS resulted in the destruction of the zeolite crystalline structure confirmed by XRD measurements (see Fig. 3), which in turn lower the surface area and pore volume of SCS. In contrast, the ASCS sample, synthesized at the higher $\mathrm{pH}$ of 4 , shows a smaller drop in BET surface area and pore volume when compared to those of $\mathrm{NH}_{4} \mathrm{Y}$ zeolite. The difference between the textural properties of the ACS and ASCS samples may be attributed to the longer aging time provided for the ASA sols to form a thicker layer around the zeolite particles in case of ASCS.

The $\mathrm{N}_{2}$ adsorption-desorption isotherms of all samples are presented in Fig. 4. The isotherms of the samples exhibit a combination of type-I and type-IV adsorption-desorption isotherms. The steep rise at $p / p_{0}<0.01$, is typically related to zeolite micropores while a hysteresis loop at lower closing point at $p /$ $p_{\mathrm{o}} \approx 0.42$ indicates that the structures of the CI catalyst and the composite samples possess a broad pore size distribution from mesopores to even interparticle macropores [22]. In addition, at the relative pressures above 0.8 , PCS shows a relatively higher $\mathrm{N}_{2}$ adsorption capacity as compared to the other samples. This may

Table 1

Textural properties of the samples.

\begin{tabular}{|c|c|c|c|c|c|c|}
\hline \multirow[t]{2}{*}{ Samples } & \multicolumn{3}{|c|}{ Surface area $\left(\mathrm{m}^{2} / \mathrm{g}\right)$} & \multicolumn{3}{|c|}{ Pore volume $(\mathrm{ml} / \mathrm{g})$} \\
\hline & Micropore $^{a}$ & Meso and macropore ${ }^{\mathrm{b}}$ & Total $^{\mathrm{c}}$ & Micropore $^{\mathrm{a}}$ & Meso and macropore ${ }^{\mathrm{b}}$ & Total $^{\mathrm{d}}$ \\
\hline $\mathrm{NH}_{4} \mathrm{Y}$ & 667 & 8 & 675 & 0.442 & 0.021 & 0.463 \\
\hline ASA & - & 196 & 196 & - & 0.126 & 0.126 \\
\hline $\mathrm{CI}$ & 300 & 69 & 369 & 0.113 & 0.049 & 0.162 \\
\hline PCS & 105 & 120 & 225 & 0.094 & 0.128 & 0.222 \\
\hline ACS & 219 & 54 & 273 & 0.078 & 0.060 & 0.138 \\
\hline SCS & - & 17 & 17 & - & 0.017 & 0.017 \\
\hline ASCS & 215 & 42 & 257 & 0.079 & 0.057 & 0.136 \\
\hline
\end{tabular}

a Micropore surface area and pore volume estimated by the $t$-plot method.

b Mesopore surface area and pore volume calculated from BJH desorption cumulative data of pores (1.7-300 nm).

c Total surface area estimated by the multiple point BET method.

d Total pore volume estimated at $p / p_{\mathrm{o}}=0.99$. 


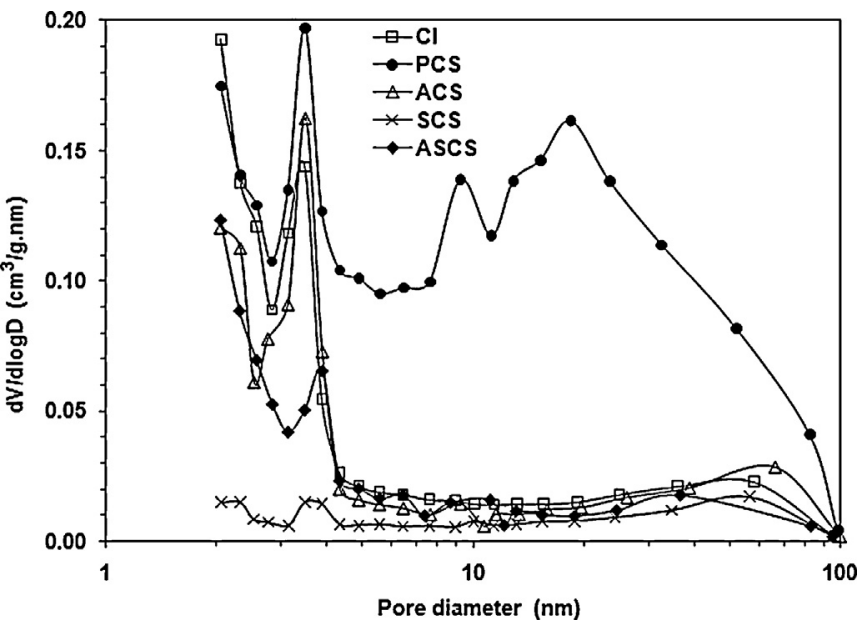

Fig. 5. BJH pore size distribution of CS composites and the $\mathrm{CI}$ catalyst.

imply the presence of more ASA meso- and macropores interparticle in the sample [23]. It is worth noting that the PCS sample contains more separate agglomerates of ASA in comparison with the other composite samples. Furthermore, less amount of nitrogen is adsorbed on SCS due to its low surface area and pore volume.

Although the $\mathrm{BJH}$ model is not often used to precisely determine the surface area of mesopores; however, it can be used to show the mesopore size distribution [24]. Fig. 5 shows the BJH pore size distribution of the CS composites and the CI catalyst. For CS composites, the narrow pore size distribution around $3.7 \mathrm{~nm}$ is related to the mesopores of ASA and a small amount of macropores with about $60 \mathrm{~nm}$ diameter is formed by aggregation of ASA particles [17]. The agglomeration of ASA happens through binding of surface hydroxyl groups $(\mathrm{Si}-\mathrm{OH})$ of neighboring ASA particles [25]. In addition, a broad range of pore sizes is observed for the PCS sample. This can be explained in analogy to what was mentioned for a relatively greater $\mathrm{N}_{2}$ adsorption capacity of PCS. The shift of pore sizes to larger values in ACSC composite, as compared to the rest of composites, is attributed to forming larger ASA particles at longer aging times. This creates larger macropores, shifting of pore size distribution to larger values in macroporous range.

$\mathrm{NH}_{3}$-TPD technique provides information on the amount and strength of acid sites by using $\mathrm{NH}_{3}$ as a basic probe molecule with a cross sectional area of $0.141 \mathrm{~nm}^{2}$ [26]. Ammonia molecule is small

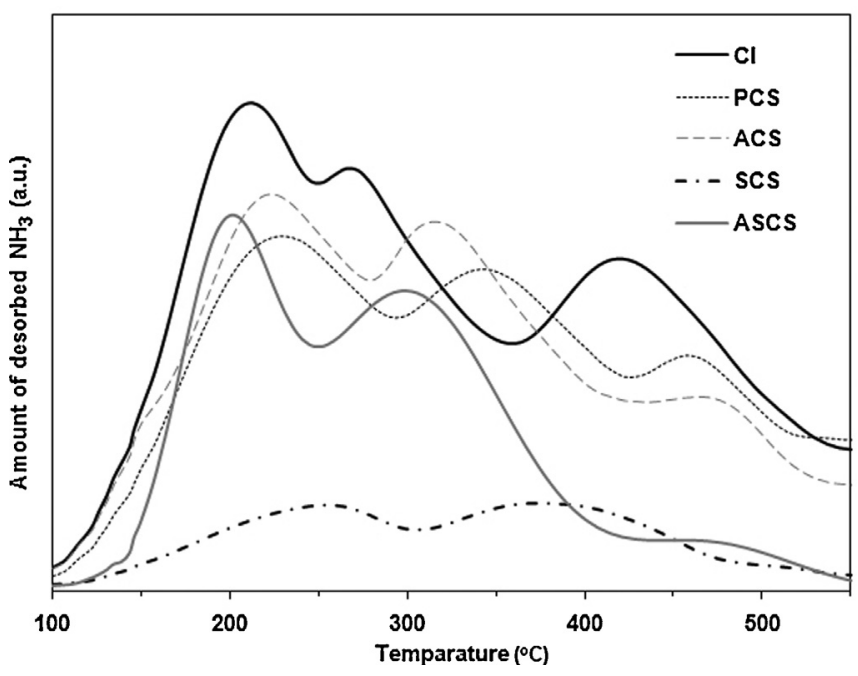

Fig. 6. $\mathrm{NH}_{3}$-TPD curves of $\mathrm{CS}$ composites and the $\mathrm{CI}$ catalyst.
Table 2

Acidic properties of the samples determined by $\mathrm{NH}_{3}$-TPD.

\begin{tabular}{lllll}
\hline Samples & \multicolumn{4}{l}{ Acidity $\left(\mathrm{mmol} \mathrm{NH}_{3} / \mathrm{g}\right.$ of sample $)( \pm 0.06)$} \\
\cline { 2 - 5 } & Weak acid & Medium acid & Strong acid & $\begin{array}{l}\text { Total acid } \\
\text { sites }\end{array}$ \\
\hline PCS & $0.362(22 \%)$ & $0.675(42 \%)$ & $0.578(36 \%)$ & 1.615 \\
ACS & $0.382(25 \%)$ & $0.732(48 \%)$ & $0.412(27 \%)$ & 1.526 \\
SCS & $0.058(35 \%)$ & $0.062(38 \%)$ & $0.045(27 \%)$ & 0.165 \\
ASCS & $0.339(31 \%)$ & $0.670(61 \%)$ & $0.094(8 \%)$ & 1.103 \\
CI & $0.465(26 \%)$ & $0.524(30 \%)$ & $0.784(44 \%)$ & 1.773 \\
\hline
\end{tabular}

enough to enter the pores of the samples and be adsorbed on their acid sites. This technique can distinguish sites by sorption strength; however, cannot differentiate between Brønsted and Lewis acid sites. The $\mathrm{NH}_{3}$-TPD profiles of the $\mathrm{CS}$ composites and the $\mathrm{CI}$ catalyst are presented in Fig. 6. The area under the $\mathrm{NH}_{3}-\mathrm{TPD}$ profile represents the amount of acid sites and the peak positions in the profile show the strength of acid sites. In order to follow the changes in the number of acid sites of different strengths, the TPD profiles were deconvoluted using Gaussian deconvolution method to provide three sub-profiles (not shown here), representing weak, medium and strong acid sites. The sub-profiles with the peak positions at $150-250,270-430$, and above $450^{\circ} \mathrm{C}$ were respectively assigned to weak, medium, and strong acid sites [27]. The amount and strength of acid sites of the samples, with a confidence level of $94 \%$, are summarized in Table 2 .

All the samples have three types of acid sites originated from their $\mathrm{NH}_{4} \mathrm{Y}$ zeolite and ASA constituents. The $\mathrm{NH}_{4} \mathrm{Y}$ zeolite has weak, medium, and strong while ASA contains only weak and medium acid sites [17]. Compared to the CI catalyst, the peak positions of the medium and strong acid sites of all the CS composites are shifted to higher temperatures, indicating that the medium and strong acid sites of the CS composites are stronger than those of the $\mathrm{CI}$ catalyst. This may imply the formation of new strong acid sites at the interface of the ASA-zeolite in which there are more interconnected pores having higher acid site density and strength in comparison with the physical mixture of the constituents of the composites [12,13,28,29]. The significant loss of acid sites in SCS may be arisen from the destruction of the zeolite crystalline structure, confirmed by XRD measurements.

\subsection{Cracking activity results}

The prepared composites were used as catalysts for cracking of TIPB molecule with the kinetic diameter of $9.4 \AA$, which is larger than the aperture of Y-zeolite micropores of $7.4 \AA$, and is bulky enough to be considered as a difficult-to-process FCC feed [30,31]. The main products of TIPB cracking are propylene, benzene, cumene, and diisopropylbenzene (DIPB) isomers [17,32]. The diffusion of TIPB molecules into the zeolite pores is of configurational type. The kinetic diameter of 1,3-DIPB, cumene, and benzene are $8.4,6.8$ and $4.9 \AA$, respectively [30,33]. DIPB isomers are considered as TIPB pre-cracking products while benzene and cumene are the products of deep cracking of TIPB molecules. Since the diffusion of TIPB into the micropores of Y-zeolite is limited, it is expected that the TIPB molecules are mostly pre-cracked on ASA acid sites and the resulting DIPB isomers, which can diffuse into the zeolite micropores, are further cracked to cumene and benzene on the stronger acid sites of the zeolite. Therefore, the better the zeolite particles are covered with the ASA particles in the composites, the higher is the yield of deep cracking products and the lower is the amount of coke formed on the samples.

The conversion of TIPB on the catalysts versus time on stream (TOS) is presented in Fig. 7. The TIPB cracking test was not done on the SCS sample due to its low acidity and surface area. TIPB 


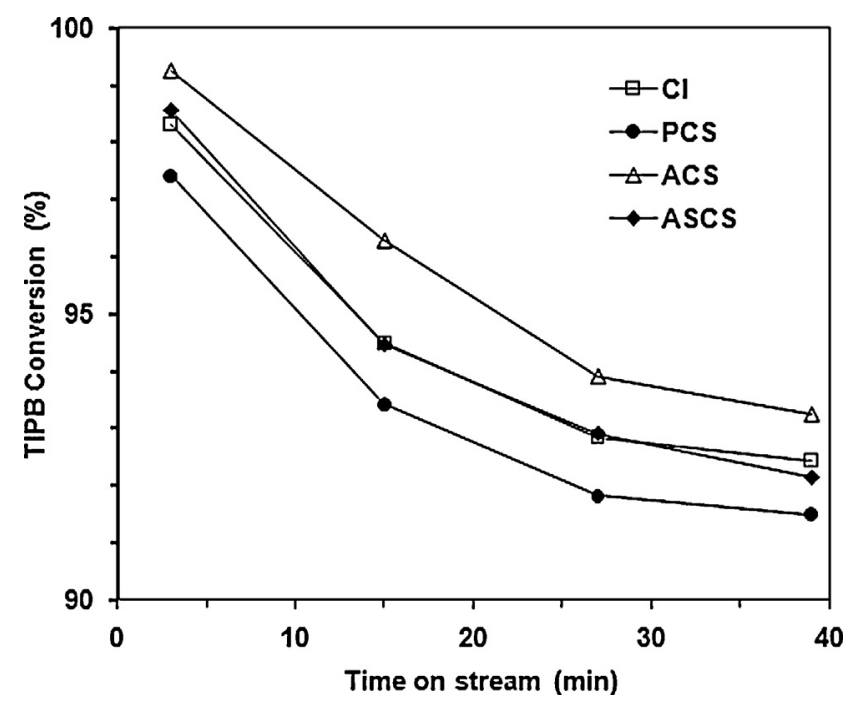

Fig. 7. Conversion of TIPB on CI and CS samples at $350^{\circ} \mathrm{C}$ versus time on stream.

Table 3

TIPB cracking activity and product distribution of the samples at 3 min time on stream.

\begin{tabular}{llllll}
\hline \multirow{2}{*}{ Samples } & Conversion (\%) & \multicolumn{4}{l}{ Molar yield $^{\mathrm{a}}(\%)$} \\
\cline { 3 - 6 } & & Propylene & Benzene & Cumene & DIPBs $^{\text {b }}$ \\
\hline PCS & 97.4 & 57.6 & 1.6 & 33.2 & 13.8 \\
ACS & 99.2 & 73.7 & 3.5 & 52.0 & 7.2 \\
ASCS & 98.5 & 68.1 & 3.8 & 54.3 & 8.8 \\
CI & 98.3 & 51.7 & 1.1 & 25.6 & 10.1 \\
\hline
\end{tabular}

${ }^{a}$ Molar yield: (molar flow of a product)/(molar flow of TIPB in feed-molar flow of TIPB in the products).

b DIPBs: the summation of 1,3-DIPB and 1,4-DIPB products.

cracking activity of the samples decreases in the order of ACS $>$ ASCS $\approx$ the CI catalyst $>$ PCS. The activity of the catalysts for TIPB cracking decreases with the same pace as TOS. During the cracking, the catalyst surface is covered with layers of coke deposit; thereby the accessible surface area decreases, active sites are coated with the deposits of coke and pores are blocked with the coke buildup [27]. At lower times on stream, all the samples are deactivated very fast via coking, indicating that the large portion of the coke is formed at the early stage of the TIPB cracking experiments.

Molar yields for various products after $3 \mathrm{~min}$ TOS are summarized in Table 3. The results show that propylene, cumene, and DIPB are the major products and benzene is the minor product, suggesting that there are three prevailing reaction steps in TIPB cracking: (1) dealkylation of TIPB to form DIPBs, (2) dealkylation of DIPB to give cumene, and (3) dealkylation of cumene to form benzene, all forming propylene [27,30,34]. Although the reactions mentioned above are dominant during the process of TIPB cracking, other reactions such as disproportionation, isomerization, and condensation may also take place, which affect gas phase product distribution and the formation of coke [35]. The yield of the deep cracking products, i.e., benzene and cumene, on ASCS, ACS, and PCS samples is respectively 117.6, 107.9 , and $30.3 \%$ higher than that of the $\mathrm{CI}$ catalyst. These results reveal that the second and third steps of the proposed cracking pathway take place more conveniently on the CS composites rather than the $\mathrm{CI}$ catalyst with respect to the fact that the structure of the CS composites is more proper for the diffusion controlled reactions.
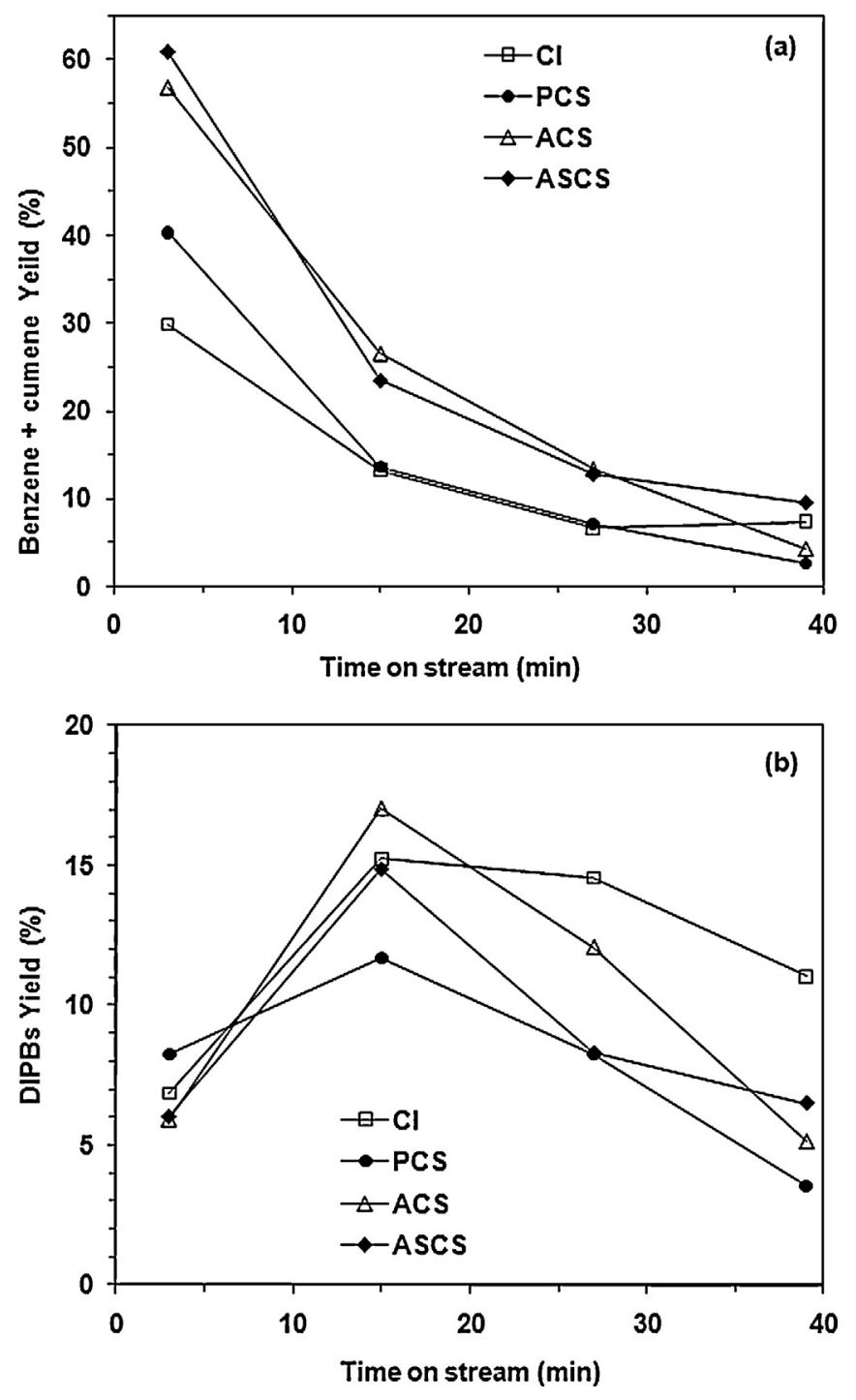

Fig. 8. Molar yields of (a) deep cracking and (b) pre-cracking products at $350^{\circ} \mathrm{C}$ versus time.

Fig. 8 shows the molar yield of the TIPB cracking products with TOS. All the CS composites show higher yields for all the products compared to the CI catalyst especially at lower TOS. The enhancement of the yield of pre-cracking and deep cracking products is ascribed to the functional ASA shell in the CS samples. This means that in the CS composites, the zeolite particles are more properly covered with the ASA nanoparticles comparing the CI catalyst. The dealkylation of TIPB and DIPB molecules proceeds readily on weak acid sites while cumene dealkylation is catalyzed by strong Brønsted acid sites [36,37]. As discussed earlier, ASA has weak and medium strength acid sites, which are accessible to TIPB molecules. Therefore, it is able to pre-crack TIPB and even DIPB isomers, which cannot easily enter into the micropores of Y-zeolite. The resulting smaller molecules can easily diffuse into the zeolite micropores where they are exposed to strong acid sites and deeply cracked to benzene. Furthermore, because of the low surface area and acid density of the ASA, the coke can rapidly cover its accessible active sites in the CS composites, resulting in rapid decrease in the yield of the pre-cracking products. At earlier TOS, DIPB isomers, and cumene molecules may be directly converted to benzene on the zeolite acid sites. At longer TOS, the strong acid 
Table 4

The carbon content and total $\mathrm{CO}_{2}$ and $\mathrm{CO}$ released in TPO of the coked samples.

\begin{tabular}{|c|c|c|c|c|c|}
\hline Samples & $\mathrm{CO}(\mu \mathrm{mol} / \mathrm{g})$ & $\mathrm{CO}_{2}(\mu \mathrm{mol} / \mathrm{g})$ & $T_{\max } \mathrm{CO}(\mathrm{C})$ & $T_{\max } \mathrm{CO}_{2}(\mathrm{C})$ & Carbon content (wt.\%) \\
\hline PCS & 418.3 & 1807.9 & 590 & 590 & 2.67 \\
\hline ACS & 994.6 & 1967.8 & 570 & 560 & 3.55 \\
\hline ASCS & 1448.7 & 3691.0 & 590 & 590 & 6.16 \\
\hline $\mathrm{CI}$ & 2069.5 & 3802.8 & 560 & 550 & 7.05 \\
\hline
\end{tabular}

sites of the zeolite are deactivated by coking and mesopores of the ASA shell are blocked with the coke buildup, resulting in the rapid drop in the yield of the deep-cracking products.

\subsection{Temperature-programmed oxidation of coked samples}

In order to investigate the amount and the type of the coke formed on the samples during the cracking experiments, the TPO technique was employed. $\mathrm{CO}_{2}$ and $\mathrm{CO}$ evolution profiles in TPO of the coked catalysts are presented in Fig. 9 and the results are summarized in Table 4. The total amount of coke and its refractoriness are obtained from areas under the peaks and their positions in the TPO profiles, respectively. It is suggested that the coke content is proportional to the density of acid sites and their accessibility to heavy molecules while the coke refractoriness is proportional to peak temperature in TPO profile $[17,18,38]$. The $\mathrm{CI}$ catalyst has the highest and the PCS sample has the lowest coke contents. The coke content of PCS, ACS, and ASCS are about 62, 50, and $13 \%$ lower than that of the $\mathrm{CI}$ catalyst. In addition, a $\mathrm{CO}_{2}$ peak of ASCS TPO profile has shifted to a higher temperature, as compared to that of $\mathrm{CI}$ catalyst, indicating the formation of slightly more
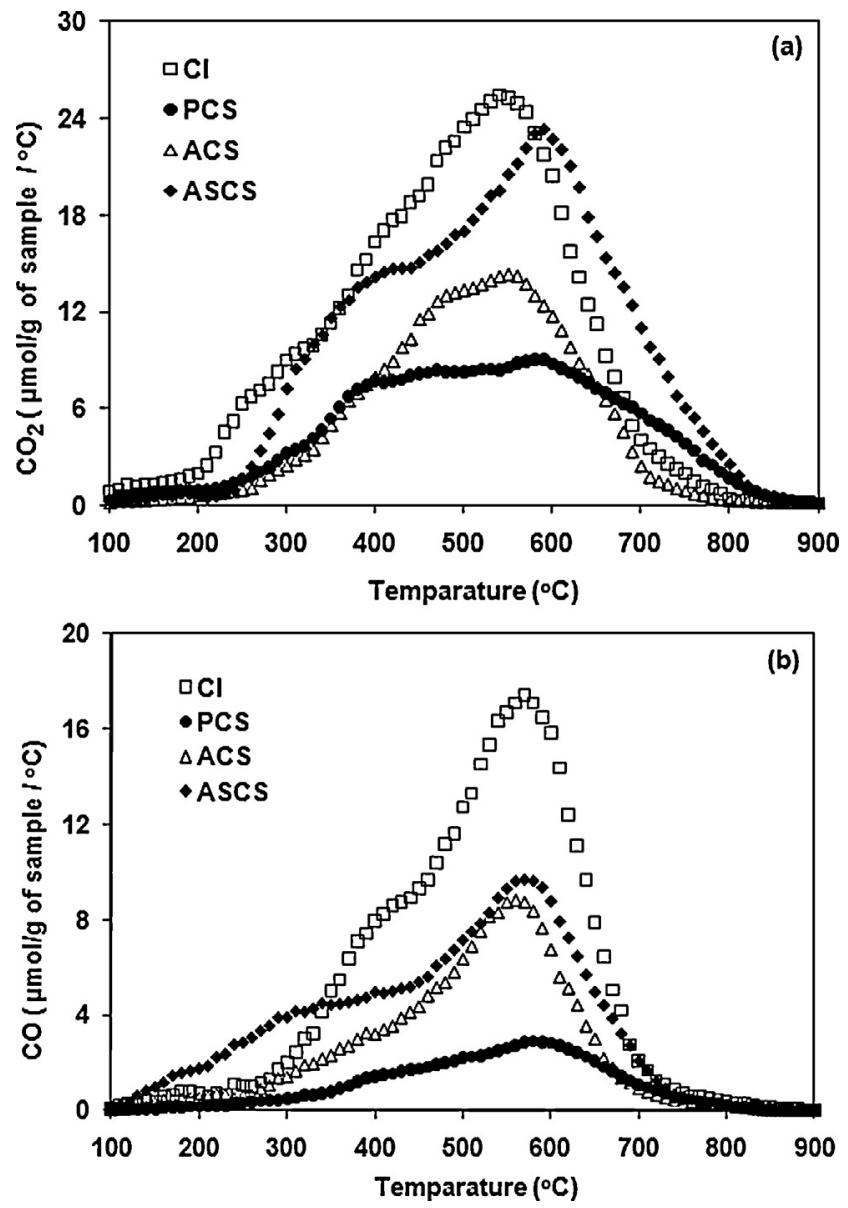

Fig. 9. The evolution of (a) $\mathrm{CO}_{2}$ and (b) $\mathrm{CO}$ during the TPO tests of coked samples. refractory coke. This may be attributed to the stronger acid sites and larger pores [18] in the ASCS sample (see Fig. 6 and Table 1). However, the total amount of coke is lower for all CS composites, as compared to $\mathrm{CI}$ catalyst.

\section{Conclusions}

In this work, the tailored catalytic composites of Y-zeolite and amorphous silica-alumina (ASA) were prepared and compared with a conventionally incorporated catalyst $(\mathrm{CI})$ in catalytic cracking of triisopropylbenzene (TIPB). The layer of ASA on the surface-charge-modified Y-zeolite particles was formed by precipitation (PCS), or deposition of ASA aggregates (ACS), sols (SCS) or sols followed by aging (ASCS). ASA particles are almost weak in acidity while the zeolite comprises of strong, medium, and weak acid sites. The activity of the sample prepared by deposition of aggregated ASA on zeolite is higher than that of CI. The TIPB molecules are pre-cracked on the acid sites of the ASA and produce lower-molecular-weight products with higher accessibility to the strong acid sites of the Y-zeolite. This results in higher (up to two times for ASCS sample) cumene and benzene yields as deep cracking products. Furthermore, significantly lower amount of coke is formed on the CS composite samples, on PSC of which it is $62 \%$ lower. The pre-cracking of bulky TIPB on ASA may protect the high density surface acid sites of the zeolite from direct exposure to TIPB molecules and is the main cause of lower of coke formation. The methods used in this study for covering the zeolite with an ASA layer, as compared to common mixing method, can tailor the FCC product distribution by heavy feed pre-cracking on the ASA layer, lower the coke formation particularly on zeolite, and therefore protect zeolite from destructive deactivation.

\section{Acknowledgement}

The authors acknowledge the National Iranian Oil Refining and Products Distribution Company for providing the financial support of this research work.

\section{References}

[1] J. Zheng, Q. Zeng, Y. Yi, Y. Wang, J. Ma, B. Qin, X. Zhang, W. Sun, R. Li, Catal. Today 168 (2011) 124-132.

[2] A. Ishihara, K. Kimura, A. Owaki, K. Inui, T. Hashimoto, H. Nasu, Catal. Commun. 28 (2012) 163-167.

[3] T. Jiang, L. Qi, M. Ji, H. Ding, Y. Li, Z. Tao, Q. Zhao, Appl. Clay Sci. 62-63 (2012) 32 40.

[4] R. Wang, H. Wang, B. Wei, W. Wang, Z. Lei, Int. J. Hydrogen Energy 35 (2010) 10081-10086

[5] X. Li, J. He, M. Meng, Y. Yoneyama, N. Tsubaki, J. Catal. 265 (2009) 26-34.

[6] J. He, Y. Yoneyama, B. Xu, N. Nishiyama, N. Tsubaki, Langmuir 21 (2005) 16991702 .

[7] G. Yang, Y. Tan, Y. Han, J. Qiu, N. Tsubaki, Catal. Commun, 9 (2008) 2520-2524.

[8] C. Mei, Y. Yeung, S. Chi Tsang, J. Phys. Chem. 113 (2009) 6074-6087.

[9] Q. Yan-ping, C. Sheng-li, D. Peng, X. Ke-qi, S. Bao-jian, J. Fuel Chem. Technol. 34 (2006) 685-689.

[10] S. Anderssona, T. Myrstad, Appl. Catal. A 170 (1998) 59-71.

[11] Y. Lu, M. He, J. Song, X. Shu, Stud. Surf. Sci. Catal. 134 (2001) 209-217.

[12] Y. Zhang, Y. Liu, Y. Li, Appl. Catal. A 345 (2008) 73-79.

[13] H. Liu, X. Bao, W. Wei, G. Shi, Microporous Mesoporous Mater. 66 (2003)117-125.

[14] Y. Zhou, Q. Wei, H. Ma, Z. Zhang, Catal. Today 125 (2007) 211-219.

[15] X. Zhang, Q. Guo, B. Qin, Z. Zhang, F. Ling, W. Sun, R. Li, Catal. Today 149 (2010) 212-217. 
[16] A. Karlsson, M. Stöcker, R. Schmidt, Microporous Mesoporous Mater. 27 (1999) 181-192.

[17] N. Hosseinpour, Y. Mortazavi, A. Bazyari, A.A. Khodadadi, Fuel Process. Technol. 90 (2009) 171-179.

[18] A. Bazyari, A.A. Khodadadi, N. Hosseinpour, Y. Mortazavi, Fuel Process. Technol. 90 (2009) 1226-1233.

[19] L.P. Wu, X. Li, Z. Yuan, Y. Chen, Catal. Commun. 11 (2009) 67-70.

[20] A. Ishihara, K. Inui, T. Hashimoto, H. Nasu, J. Catal. 295 (2012) 81-90.

[21] R.L. Hartman, H.S. Fogler, Langmuir 23 (2007) 5477-5484.

[22] S. Storck, H. Bretinger, W.F. Maier, Appl. Catal. A 174 (1998) 137-146.

[23] J. Zheng, X. Zhang, Y. Zhang, J. Ma, R. Li, Microporous Mesoporous Mater. 122 (2009) 264-269.

[24] P. Wang, B. Shen, J. Gao, Catal. Commun. 8 (2007) 1161-1166.

[25] C.S. Triantafillidis, A.G. Vlessidis, N.P. Evmiridis, Ind. Eng. Chem. Res. 39 (2000) 307-319.

[26] A.M. Venezia, V. La Parola, B. Pawelec, J.L.G. Fierro, Appl. Catal. A 264 (2004) $43-51$.
[27] N. Hosseinpour, A.A. Khodadadi, Y. Mortazavi, A. Bazyari, Appl. Catal. A 353 (2009) $271-281$.

[28] Q. Huo, T. Dou, Z. Zhao, H. Pan, Appl. Catal. A 381 (2010) 101-108.

[29] J. Zheng, X. Zhang, Y. Wang, Y. Bai, W. Sun, R. Li, J. Porous Mater. 16 (2009) 731-736.

[30] S. Al-Khattaf, H. de Lasa, Appl. Catal. A 226 (2002) 139-153.

[31] J. Qi, T. Zhao, X. Xu, F. Li, G. Sun, J. Porous Mater. 18 (2011) 69-81.

[32] S. Al-Khattaf, J.A. Atias, K. Jarosch, H. de Lasa, Chem. Eng. Sci. 57 (2002) 49094920.

[33] F.S. Xiao, Top. Catal. 35 (2005) 9-24.

[34] J. Qi, T. Zhao, X. Xu, F. Li, G. Sun, C. Miao, H. Wang, Catal. Commun. 10 (2009) 15231528.

[35] T.C. Tsaia, S.B. Liu, I. Wang, Appl. Catal. A 181 (1999) 355-398.

[36] L. Frunz, R. Prins, G.D. Pirngruber, Microporous Mesoporous Mater. 88 (2006) $152-162$.

[37] N. Katada, Y. Kageyamaa, K. Takahara, T. Kanai, H.A. Beguma, M. Niwa, J. Mol. Catal. A Chem. 211 (2004) 119-130.

[38] B. Wang, G. Manos, Ind. Eng. Chem. Res. 46 (2007) 7977-7983. 